\title{
Experimentant els avantatges del treball en grup del professorat
}

\author{
Anna M. Plarromaní, M. Tura Puigvert, Roser Reina \\ aplarrom@gmail.com
}

La constitució d'un grup de treball estable entre professors especialistes permet introduir innovacions en la pràctica docent de manera eficaç. La cooperació entre centres propers per realitzar activitats experimentals de llarg abast resol molts dels problemes de caràcter pràctic que sorgeixen en els centres de secundària.

Paraules clau: grup de treball, experiències compartides, REVIR, intercanvi d'experiències, elaboració propostes didàctiques, aula de ciències

\section{Introducció}

Fa ja alguns anys, uns quants professors i professores de Física i Química del Maresme ens vàrem constituir en grup de treball amb l'objectiu d'intercanviar experiències realitzades a diversos centres de Secundària i mirar de millorar així la nostra activitat docent. Vàrem demanar el suport del CRP i de l'ICE de la UAB per tal de gaudir dels avantatges de la constitució d'un grup de treball estable.

Volem comunicar els resultats de la nostra experiència i generalitzar les nostres motivacions amb la finalitat que pugui servir per animar altres companys i companyes a treballar en grup i compartir experiències.

\section{Necessitat de compartir experiències docents}

El grup de ciències Intercanvi d'experiències $i$ elaboració de propostes didàctiques va sorgir de la inquietud de diferents professors i professores de Física i Química que estàvem interessats en compartir l'aprenentatge de noves tecnologies i renovar les activitats pràctiques que proposàvem a l'alumnat. Es tractava de preparar experiències per a les classes pràctiques, que majoritàriament incorporessin l'ús de les tecnologies de la informació i de la comunicació així com altres tècniques audiovisuals.

De forma esporàdica, quan era necessari, demanàvem assessorament extern de persones ex- pertes en alguna de les tecnologies que volíem incorporar.

\section{Evolució dels grups i realització de pràctiques intercentres}

Durant el curs 2007-08 diferents professionals es van anar incorporant al nostre grup i, per raons diverses, hi han trobat un bon suport per a la seva activitat diària. Entre elles n'hi havia que provenien de camps de treball científic especialitzat però distant de la docència, per a les quals el coneixement tècnic o científic no era el problema principal. La seva mancança residia en l'adaptació d'aquells coneixements a la realitat sociocultural de l'aula i a la complexitat dels processos cognitius.

D'altres, incorporades a la docència just acabats els seus estudis universitaris, no tenien més referent de com és una aula plena d'alumnes de secundària obligatòria que el propi record distorsionat de quan van ser estudiants. El món ha canviat molt ràpidament i no els podia servir de model ni els records de la seva aula de secundària ni molt menys els més recents dels seus estudis universitaris.

Per últim, hi ha el perfil del professorat ja veterà, que després d'anys de repetir el que havia estat per a ell "el programa oficial", amb l'ajut del llibre de text i guions de pràctiques de laboratori, s'adona que la classe se li escola entre els dits i no sap com comunicar amb el nou tipus d'alumnat. És professorat que sent la necessitat de canviar i cerca una altra manera de fer. 
Per a tots els participants, el grup d'intercanvi d'experiències, on tranquil-lament parlem de com podem millorar petites coses de l'activitat quotidiana, ha estat molt reconfortant i ha afavorit canvis reals en la manera de treballar.

Transcrivim a continuació les vivències de la doctora Roser Reina, amb experiència en recerca $i$ en docència universitària, que aquest curs s'ha incorporat al grup de treball de Mataró, pel fet que pertany a I'IES Alexandre Satorras i està interessada en conèixer de prop la realitat dels instituts de la zona:

"El fet de participar en un grup de pràctica reflexiva m'ha ensenyat a planificar d'una manera més acurada com impartir la docència.

Per a mi, el gran repte va ser quan vaig fer el canvi des del món universitari, on els fonaments de la docència eren els coneixements conceptuals a impartir. En cap moment et planteges el com $i$ el per què ho fas d'una manera o d'una altra. És a dir, l'alumne ha d'assolir aquells coneixements i és la seva responsabilitat aconseguir-ho.

Certament, la percepció i valoració del docent quant a les classes que imparteix és important. Moltes vegades un mateix s'adona que allò que vol comunicar no arriba i cal estar disposat a provar metodologies i materials extres perquè l'alumnat se senti més segur. Però aquesta no és una tasca imprescindible en el docent universitari, i en canvi, sí que ho és en el de secundària.

En resum, l'enfocament tradicional en la docència universitària recau en la transmissió d'una sèrie de conceptes $i$ en el seu assoliment. És possible que amb els nous plans d'estudis universitaris tot vagi canviant $i$ el professorat s'hagi de plantejar més sovint el com $i$ el per què de la manera d'ensenyar.

El canvi a secundària em comportà un nou repte, ja que cal una profunda autoanàlisi d'allò que vols ensenyar. Evidentment es transmeten coneixements conceptuals, però es medita molt bé el com ho faré, com m'ajudaré per fer-ho, perquè necessito aquests recursos $i$ no altres de diferents, com els utilitzaré amb els alumnes, què els faré fer, com els avaluaré. Tot adreçat a promoure amb eficàcia el canvi en les idees de l'alumnat cap a models científics útils.

Tanmateix, si comparo la meva activitat docent en els dos àmbits, observo que dins el món de la secundària cal ésser més sensible a les reaccions dels interlocutors i cal reflexionar sobre la conveniència de cada tipus d'activitat. L'adaptació d'activitats a la complexitat del dia a dia és constant. El diàleg i la cooperació entre l'alumnat, les pautes d'autoavaluació, són part de les estratègies que cal planificar i aplicar amb constància.
És cert que, com a docents, som capaços de fer de manera individual aquest acte reflexiu, però la participació en un grup de treball permet expressar les inquietuds, les insatisfaccions $i$ també els èxits entre iguals; permet adonar-nos que no estem sols $i$ ens fa sentir més segurs en la presa de decisions".

\section{Realització de pràctiques intercentres}

\section{El punt de partida}

Alguns professors havíem portat els alumnes a les sessions de pràctiques ofertes des de les universitats, on es disposa de material actualitzat i ben preparat, de temps i de motivació (activitats contextualitzades, interessants i amb recursos suficients). Aquestes activitats i principalment la manera amb què es portaven a terme van ser valorades molt positivament pel professorat i per l'alumnat. Per exemple, el Projecte REVIR del CRECIM de la UAB, Fem química al laboratori de la UB, Els dissabtes de la química de la UdG, Els dissabtes de la física de la UAB, Pràctiques de física de la UB, programa LINK de la EUPM, etc.

El Projecte REVIR organitza sessions pràctiques de tot un matí amb ús de les TIC, i té uns protocols molt ben elaborats i contrastats després d'alguns anys d'experiència. Els bons resultats d'aquestes sessions ens van animar a traslladar el model REVIR a la nostre ciutat durant el curs 200708. Organitzar-les en un entorn més proper als Centres estalviava els costos de desplaçament $\mathrm{i}$ potenciava els recursos humans i materials dels Centres de batxillerat.

\section{Els participants}

En el projecte que hem portat a terme durant el curs 2007-08 hi hem participat:

- 3 Instituts

- 9 professors

- alumnes:

$\begin{array}{ll}71 \text { Física } & \text { 1r batxillerat } \\ 58 \text { Química } & \text { 2n batxillerat } \\ 48 \text { Física } & \text { 2n batxillerat }\end{array}$

Durant el curs 2008-09 hi estem participant:

- 6 Instituts

- 9 professors

- alumnes:

$\begin{array}{ll}85 \text { Física } & \text { 1r batxillerat } \\ \text { 118 Química } & \text { 1r batxillerat } \\ 85 \text { Química } & \text { 2n batxillerat } \\ \text { 46 Física } & \text { 2n batxillerat }\end{array}$




\section{Com ens organitzem}

Cada Centre prepara una pràctica per als alumnes de tots els professors participants, la qual ha estat discutida i adaptada pels integrants del grup de treball.

En la redacció dels protocols s'ha intentat que els alumnes puguin construir les seves idees sobre els conceptes, introduint preguntes que generin discussió.

S'ha tingut en compte el moment idoni per portar a terme l'activitat amb els alumnes d'acord amb la temporalització de la matèria.

S'ha elaborat un calendari i un horari per cada una de les pràctiques, segons les disponibilitats horàries dels professors i dels laboratoris.

El professor o la professora del Centre organitzador presenta la pràctica als alumnes i els professors acompanyants fan de colllaboradors.

Prèviament s'ha fet una llista del material per realitzar la pràctica i s'ha previst el material que els professors dels Centres visitants han de portar per complementar el del centre organitzador (consoles, sensors, testers...)

S'han elaborat qüestionaris per l'alumnat a fi de fer una valoració dels resultats i formular propostes de millora.

\section{Relació d'activitats pràctiques}

\section{1er Trimestre \\ Física 1r Batxillerat. Cinemàtica \\ IES Alexandre Satorras}

Projecte REVIR: Educació Vial-1 per a alumnes de Batxillerat

1. Treball pràctic a partir de la captació de dades de vídeo digital (VBL). Estudi cinemàtic del xoc frontal d'un vehicle. Com minimitzar les lesions en un xoc frontal?

2. Simulació del xoc d'un vehicle amb "Interactive Phaysics". Importància del bon estat dels frens, de guardar distància entre vehicles i de la bona capacitat de reacció del conductor.

La pràctica $E d$. Vial-1 la fa cada professor en el seu centre amb els seus alumnes.

Projecte REVIR: Educació Vial-2 per a alumnes de Batxillerat

1. Experiència de laboratori amb captador de dades. De què depèn que la distància mínima de seguretat entre dos vehicles sigui més o menys gran?

Al laboratori de l'IES Satorras.
2. Simulació amb "Interactive Physics". Com fer que dos cotxes no xoquin?

La fa cada professor en el seu centre amb els seus alumnes.

\section{2n Trimestre}

Química 1r batxillerat. Cinètica química IES Alexandre Satorras

1. Reaccions amb tub d'assaig sobre la influència en la velocitat de reacció del grau de divisió, la concentració, la temperatura $i$ els catalitzadors. Com podem fer que una mateixa reacció sigui més ràpida 0 més lenta?

2. Seguiment de la variació de pressió amb Multilab. Com controlar la velocitat d'una reacció en la qual es desprèn un gas?

Física 2n Batxillerat. Electromagnetisme IES Damià Campeny

1. Experiència de laboratori amb captador de dades. Com és el camp magnètic creat per un solenoide? Quina és la relació entre la intensitat del camp magnètic $B$ i la intensitat del corrent? De quins factors depèn la inducció electromagnètica?

\section{3r Trimestre \\ Química 2n Batxillerat. Reaccions redox IES Pla d'en Boet}

1. De la química a l'electricitat. De què depèn el voltatge d'una pila? Diferents tipus de piles: pila Volta, pila Daniell, piles casolanes: pila "neula" (Mg$\mathrm{Cu})$, pila amb llapis i maquineta...

2. De l'electricitat a la química. De què depèn la quantitat de zinc que s'obté per electròlisi del sulfat de zinc? Procés industrial d'obtenció d'un metall a escala de laboratori. Càlcul del rendiment . Experiència $a m b$ captació de dades per ordinador.

3. Transformacions energètiques en el cotxe d'hidrogen. Com podem moure un cotxe amb energia solar?

\section{Com valorem aquest experiència}

Tant els professors com els alumnes que hi han participat hem valorat positivament el fet de poder fer una activitat pràctica comptant amb més temps, més dotació i més professorat. Alhora, la selecció dels continguts i la proposta d'activitats s'han anat 
discutint i modificant després d'analitzar els resultats pràctics assolits.

Atès el creixement que ha tingut, proposem mantenir la mateixa organització en el futur.

El principal inconvenient és que es basa exclusivament en el voluntarisme del professorat, qui ha d'aportar temps de dedicació, a més a més de les hores corresponents al treball presencial en el grup. Considerem que per tal que activitats d'aquesta mena tinguin continuiltat el professorat ha de rebre suport econòmic i valoració professional.

\section{Generalització de l'experiència}

\section{Motivacions per formar un grup proper}

El professorat sent la necessitat d'organitzar-se per esmenar els problemes derivats d'un mapa escolar de centres que ha primat l'atomització de centres de secundària, que ha desvirtuat els equips interns d'especialistes en cada matèria.

Amb un alumnat tan canviant $\mathrm{i}$ amb un professorat cada cop més divers en la seva formació acadèmica, el grup de referència on es pot compartir l'experiència docent dóna seguretat i millora l'activitat quotidiana que es desenvolupa a les aules.

Els problemes que ens trobem en la pràctica diària són principalment els següents:

- Hi ha poques persones de cada especialitat en un mateix centre de treball.

- Les noves tecnologies són eines molt atractives per a l'alumnat i que necessiten hores de d'aprenentatge i de preparació per adequar-les a les activitats d'aprenentatge.

- De vegades els equipaments de què disposa cada centre són insuficients i actualment la renovació no és prou ràpida i alguns d'ells ja van quedant obsolets.

- És manifesta la necessitat de comunicar als altres les experiències positives que cada professional va descobrint per poder compartir els resultats i millorar la pràctica docent col-lectiva.

\section{La formació d'un grup estable}

La tasca de tots aquests anys ens permet afirmar que la formació d'un grup de treball estable i proper té els següents avantatges:

- El grup estable afavoreix la comunicació.

- S'agilita la resolució de dificultats tècniques.

- El professorat se sent motivat a innovar i disposa d'eines per observar la pràctica quotidiana $i$ detectar-ne els punts forts i febles.
- La comunicació en grup estimula la posada en pràctica d'experiències innovadores.

- En grup es fa més fàcil l'edició i correcció de protocols $i$, en conseqüència, es renoven amb més facilitat els arxius d'aplicació didàctica existents en el centre de treball.

- L'aprenentatge presencial i en un grup estable és més agradable i gratificant.

- El treball a cada centre permet visualitzar com s'organitza i es distribueix el material en els espais dels laboratoris segons les possibilitats de cada lloc. Al mateix temps s'observa i es comenta la manera de treballar de cada seminari.

- A les reunions de treball es pot comentar i comparar la gestió d'hores dedicades a cada matèria en els diferents instituts.

- També és important conèixer de prop com es resolen la relació i coordinació amb els altres departaments de cada centre.

- El treball conjunt entre professors de centres públics i privats ens ha permès conèixer més centres del nostre entorn, establir comunicació entre el professorat de diversos centres, que d'altra manera no haguéssim tingut ocasió de fer-ho, i treballar plegats.

\section{Conclusió}

La realització del treball en grup, sigui en seminaris d'innovació curricular, elaboració de materials, realització d'experiències o seguiment de propostes de recerca, permet fer una reflexió entre iguals, compartir coneixements i comunicar idees.

Més enllà de les coordinacions pedagògiques $\mathrm{i}$ dels equips docents dels centres, imprescindibles per dur a terme una bona planificació per competències, els grups de treball de ciències formats per professorat de diversos centres propers permeten la cooperació i el creixement mutu en unes condicions que representen poc cost i molt benefici.

Les persones amb qui hem compartit les diferents modalitats de treball en grup són les següents: Carme Aymerich, Carolina Estudillo, Joan Hens, Miquel Galceran, Anna Grancelli, Àngel González, Núria Lorente, Llorenç Martínez, Enric Fuster, Mercè Salvia, Isidre Vilà.

Un altre àmbit on hem gaudit del treball en grup és en l'organització de les Jornades Científiques de Mataró, que ja tenim en la seva sisena edició. Per a la mostra de Ciència al Carrer, la preparació d'activitats de divulgació per a tota la ciutadania ens obliga a contrastar les nostres maneres d'entendre la ciència i aprenem els uns dels altres. 


\section{Bibliografia}

Borràs, G. Fez, I. Aliberas, J Mirandes, J. Lloret, M. Nistal, M. (2008) Formació del professorat per a la innovació basada en la pràctica reflexiva. Ciències, número 9.

Jiménez Pérez, R. (2004). Trabajo de investigación. La práctica, la reflexión sobre la práctica y el análisis de los obstáculos para el desarrollo profesional de profesores de Ciencias Experimentales. Documento inédito. Universidad de Huelva.

Marx, R.W., Freeman, J., Krajcik, J. y Blumenfed, P. (1998). Profesional development of science education. En B. J. Fraser y K. G. Tobin (Ed.) International handbook of science education, 667-681. Dordrecht: Kluwer.

Membiela, P. (2002). Investigación-acción en el desarrollo de proyectos curriculares innovadores de ciencias. Enseñanza de las Ciencias, 20 (3), 443-450.

Pintó, R. (2002) El trabajo experimental con nuevas tecnologías. Aula de Innovación educativa.

Vázquez, B., Jiménez-Pérez, R. i Mellado, V. (2008). Cómo podemos llevar a cabo una investigación-acción para mejorar la pràctica en el aula de ciencias? Ensino Ciencias, 2008. 